\title{
Start Walking! How to Boost Sustainable Mode Choice-Psychological Measures to Support a Shift from Individual Car Use to More Sustainable Traffic Modes
}

\author{
Ralf Risser * and Matus Sucha \\ Department of Psychology, Palacky University Olomouc, Krizkovskeho 8, 77147 Olomouc, Czech Republic; \\ matus.sucha@upol.cz \\ * Correspondence: ralf.risser@richal.at
}

Received: 4 December 2019; Accepted: 5 January 2020; Published: 11 January 2020

\begin{abstract}
Transport is one of the sectors that contributes to global warming. To tackle this issue, one of the most important tasks is to enhance/support a mode shift from individual car use to more sustainable traffic modes. To achieve this, psychology-based measures are needed. We need to understand what keeps people from walking, and what motivates people who do walk to do so, or to define the barriers and the preconditions that are needed for walking or cycling. These preconditions are perceived in a different way by different people. As the motivation of individual citizens differs greatly, the preconditions have to be targeted precisely. In this paper a scheme is presented that deals with this issue-i.e., to enhance/support a mode shift to sustainable traffic modes with the following steps: To identify and improve the preconditions for walking; to communicate information, and; to provide opportunities or incentives. As a theoretical background we use a classical marketing model presented by Philip Kotler, which has strong connections with communication and social psychology. Through the case of supporting sustainable traffic modes-the product which will be "sold" - we present the different steps of the model (information, product, communication, incentives, and distribution). With all aspects we emphasize that a holistic approach (a combination of all these aspects and steps) is necessary for a successful marketing process that in fact makes citizens "buy" the idea of walking (more). The main suggestion of this paper is to implement the steps suggested in it in the frame of a pilot project in a city or a province and then to evaluate. Evidence that the suggested measures work when applied appropriately and-as strongly underlined—in a concerted manner can only be achieved by trying in practice.
\end{abstract}

Keywords: sustainable traffic modes; walking; mode choice; traffic psychology; pedestrians

\section{Introduction}

Among other things, it is necessary to change mode choice in order to achieve improvements concerning global warming. In this paper we suggest a number of coordinated psychological measures in order to achieve that goal. Transport is a sector that contributes greatly to global warming [1]. Transportation produces roughly 23 percent of the global $\mathrm{CO}_{2}$ emissions from fuel combustion. More alarmingly, transportation is the fastest growing consumer of fossil fuels and the fastest growing source of $\mathrm{CO}_{2}$ emissions. With rapid urbanization in developing countries, energy consumption and $\mathrm{CO}_{2}$ emissions by urban transport are increasing rapidly [2]. In order to achieve an improvement in this sector, hundreds of millions of citizens need to change their mode choice-a shift from individual car use to more sustainable traffic modes, such as walking or cycling. This will not be possible without cooperation from the side of the citizens. As many of them as possible need to modify their own mode 
choice. To achieve this goal, we need to use psychological measures to motivate citizens to change. It is necessary to understand that it is worthwhile to strive for this goal: $15 \%$ to $20 \%$ of all car trips in the OECD countries are shorter than $1 \mathrm{~km}$ [3]. Also the distance to the public transport stations and stops is short for considerable portions of the population in the OECD [4]. Thus, the potential for a change from car use to walking or to walking and public transport use is considerable.

There is solid empirical evidence on how to support an active mode choice, including psychological aspects $[5,6]$. The goal of this paper is to follow this evidence and to present in a holistic way how to communicate with citizens in order to increase the probability that a greater proportion of them would listen and act in the wished-for way. Here, the "wished-for way" is a change from using a car for very short trips $<1.5 \mathrm{~km}$ to walking such short distances ( $20 \mathrm{~min}^{\prime}$ walk; between $15 \%$ and $20 \%$ of all car trips in industrial countries; e.g., [7,8].

The starting point to achieve success in the sense displayed above is to understand two things; what keeps people from walking, and what motivates people who do walk to do so? The answers to the first question might show that yet another question has to be asked: What is it that makes the car so attractive that even the shortest distance is covered by driving it and that we neglect our most natural way of moving about? Once we have understood (better) what motivates people to walk and what keeps them from walking, society can start improving the preconditions for walking, i.e., implementing more often and more regularly the preconditions that have proven to be supportive for walking, on both the structural (e.g., infrastructure friendly to pedestrians) and the individual level (e.g., parents as role models as citizens who take responsibility for sustainability). "Preconditions" could refer to a variety of domains: to the design of infrastructure (e.g., broad sidewalks) to the public space (e.g., reasonable distances to be covered by active modes), to traffic management and the legal and administrative circumstances, or to children's education and socialization with respect to sustainable traffic $[9,10]$.

However, "objective" preconditions are in no way perceived in the same way by everybody [11]. There are certainly different ways to look at those preconditions and to appreciate them. In other words, these "outside stimuli", the preconditions, must match the inner "motivation" of citizens in order to be noticed and to have the power to change their behavior. As the motivation of individual citizens differs greatly, the preconditions have to be targeted precisely. Details could play a role in making different people look at the given conditions in different ways, but also details on the side of the citizens; what is a "short trip" in the eyes of one person could be seen as "too far" by another person. Obese persons may find walking very uncomfortable. However, erroneous information about walking, i.e., a lack of information concerning the positive effects of walking, also plays an important role. For instance, many people think that walking "takes too much time" but they regularly overestimate the time it takes. Moreover, many citizens are obviously not aware how well-spent this time is with respect to health, to fitness, and concerning positive effects on one's mood. Behind different ways of appreciating preconditions, i.e., of appreciating walking and its advantages, there could also lie a kind of Catch22-dilemma: someone who does not walk cannot feel the immediate advantages to their well-being that walking generates, and someone who does not feel the advantages of walking will not walk voluntarily. Appealing to the intelligence of people is always possible but it is a more difficult way of convincing people to change their behavior. Nowadays we can observe these trends to prefer behavior which requires self-denial and "starting energy" over behaviors which produce "instant" pleasure, for example in gastronomy (declining revenues of fast food restaurants) or in increasing interest in life balance activities, such as yoga or tai-chi [12] (Wang, Lee, Wu, Benson, Fricchione, Wang, \& Yeung, 2014). For a summary of all these aspects and arguments see Methorst at al. [13], who compiled the state of the art in the frame of the COST project.

Below, a scheme will be presented that in our eyes has the potential to solve some of the problems hinted at above: To identify and improve the preconditions for walking in such a way that (more) citizens will find those preconditions supportive (matching their motives); to communicate information (facts, figures, and arguments) so that people are prepared to look differently at walking (e.g., that 
active walkers feel reinforced), and to provide opportunities or incentives for people who hitherto have walked very little to try out walking on more and more occasions and to find out how it feels. This would probably not work for everybody but would help to convince some of them. We will thus rely on a couple of psychological and marketing theories and approaches that will be discussed briefly in the next section.

\section{Theoretical Background}

The most cited and well known model depicting a way of convincing people to do certain defined things is the marketing model presented by Philip Kotler and colleagues in his book Marketing [14]. For the purpose of this work we will refer to this model. The goal of marketing is to convince people to "buy" something, to put it bluntly. In contrast to trying to sell food, or clothes, or holiday packages, or other goods and services, non-profit or social marketing tries to change behavior in a wished-for way; to cater for something, to adopt a certain behavior, to support an idea, to adhere to certain norms. One could say that non-profit marketing wants to sell ideas. This would fit nicely together with the goal that our concept paper wants to support; to sell the idea of walking more, more regularly, for longer distances, with more pleasure, and with more self-assuredness. The value of walking should become clear to large portions of the public, adding to attempts that already have been made in this respect. Scientific articles that screened literature concerning the effect of measures, like the one of Ogilvie, Egan, Hamilton, \& Petticrew [15] found some evidence that targeted behavior change programs can achieve a shift of mode choice of up to $5 \%$. In a similar study, Ogilvie, Foster, Rothnie, Cavill, Hamilton, Fitzsimons, \& Mutrie [16] showed evidence that focused interventions at workplaces, in schools or communities could result in much higher effects (up to $60 \%$ ). However, these were typically isolated studies of subgroups in a very special context. However, there was agreement that chances are best when the addressed groups' view on preconditions for a change is well considered. Concerning cycling, Forsyth \& Krizek [17] came to the same conclusion; the cyclists' point of view needs to be considered well should changes in the cycling network and infrastructure be effective. The point that is relevant for the concept paper presented here is that none of the studies analyzed referred to any projects that would address preconditions for a behavior change and test the potentials of concerted changes of those preconditions in a more holistic way.

The social image of walking should be corrected, e.g., from being a poor people's mode to being seen as something that clever people do-of course within the frame of the speeds and distances that walking allows. The individual gains that can be achieved by walking should become transparent, from better health and fitness to better mood. Even something which is usually perceived as a negative aspect of walking - i.e., slowness — can be sold as something positive: when moving slowly, we have time to perceive our surroundings, to meet and greet people, to think in detail, i.e., to let our thoughts flow $[18,19]$.

Persons dealing with mobility and the necessities of mode choice, including public health professionals, often speak of "having to renounce something" when they appeal for a change of mobility behavior away from car use, i.e., for replacing short car trips (e.g., $<1.5 \mathrm{~km}=\sim 20 \mathrm{~min}$ ) with walking. We would like to point out a different principle. Without proof at hand, but on the basis of the knowledge that rewards are necessary for learning new behavior, we are convinced that appeals for renunciation will not work, or only for idealists who gain a reward from the idea that they are doing something good for the environment. This idea is, in principle, rewarding for many people, but we assume that it is not rewarding enough to make many people change their everyday behavior. Instead of trying to convince people to renounce something we suggest pointing out all the positive consequences walking has, not only for society but also, and especially, for each individual. For every possible barrier a positive counter-argument has to be presented, with a focus on the health, wealth, or comfort of each individual. It is important that these positive aspects have to be visible and measurable (e.g., by a fitness bracelet measuring the number of steps per day and the health and fitness advantages thus produced). 
The problem is that many people do not know of the advantages of walking, both because they have never heard of them so far (or did not pay attention) and/or because they have never experienced them so far. Even if they understand that walking is better for them and the environment this is far from sufficient to make people walk, as Brownson et al. [20] and Pooley [21] could show. If knowing would be sufficient there would be no smoking physicians. It is easy to understand that this argument is valid mainly for people who only walk the strictly necessary routes to and from their parked car or to and from public transport stops. We would talk of those people as "those who do not use walking as a transport mode". "People who walk (already)" would be those that walk regularly from A to B, or along routes that could also be covered by car or by public transport, people who have no car or who do not use a car in the city, etc. There is no strict definition of a "walker", but the way to deal with this could be to imagine "walkers", or "people who walk regularly", as those who say that they consider themselves to be regular walkers, in contrast to those who would deny that. Anyway, people who are already "walkers" do not need to be convinced. They know how walking feels and they walk regularly because it is rewarding for them, unless they belong to the group of those who have no other option than to walk (and thus maybe would like to change this situation). However, even walkers-including those who are forced to walk-can profit from being provided with information that puts walking in a much better light than it is usually seen in. Being rewarded for something that one already does improves self-assuredness and supports self-efficacy [22].

To sum up, to "sell" the idea of walking means to give walking value and to make it appear and be perceived as profitable both for society and for each individual. The stress has to be on the benefits that accrue to the individual and how they can be "seen" or "measured", but most of all how they can be "felt" by those who do not practice walking at the moment. The goal of such activities is to convince people who are not walkers or who walk little to walk more and more regularly, and to support and reward people who already walk regularly at the moment and, thus, to increase their self-assuredness. People who walk need to understand that they are not second-class citizens, nor second-class road users, as coined in the frame of the EU project Walking and cycling instead of short car-trips-WALCYNG [7]. Instead, they are "new smart citizens", who do not need to rely, or to be dependent, on the car [23]. They are free, independent, and intelligent. Of course, if distances that people have to cover are too long for walking and if, in addition, there is no appropriate public transport service then walking is no option. In this case we would have to open another chapter about appropriate public transport which, however, is not part of this paper.

This paper is a concept paper, whose aim is to present a theoretical concept. In this case a holistic, evidence based approach to support, and advocate for, a wished for behavior change of citizens, so that (more) people walk (more). As far as the authors know, this concept was not tested in any city or country. The aim of this work is to deliver a practical approach for decision makers or municipality officials which helps them to design, to implement and most of all to communicate interventions which will boost active traffic modes, especially walking.

\section{The Model}

The theoretical basis of this paper is closely associated with the marketing model, a communication model derived from the domain of social psychology, the most influential piece of literature in this relation being by Philip Kotler [14]. The heart of this model (Figure 1) is the axiomatic assumption that all measures targeting individuals with the goal of making them change their behavior are based on a sound understanding of these individuals, or customers, in our case road users or citizens, or more concretely their motivations, attitudes, habits, needs, wishes, barriers. The role of all psychological processes which "lay behind the behavior" are extensively documented in the recent literature [24]. Consequently, all the work associated with the marketing model starts with interaction with the target groups in order to learn about them and their motivations. Appropriate measures to do this are measures of research into motives, such as focus group interviews, narrative interviews, etc. All further marketing steps-product design and improvement, communication, and incentivizing and distribution 
activities-have to be based on such information. The reason is that under this condition it can be assured that the measures will be accepted and appreciated by the target groups.

- Information (citizens' motivational status): Learn about road users $\rightarrow$ precondition for fulfilling needs and avoiding barriers. You need to learn as much as possible about the existing and potential customers for the product and to systematically collect information about their attitudes and motives (needs, interests, moral concepts, and so on).

- Product: Define what is to be marketed and propose clear objectives. Pinpoint the precise behavioural change that you want to achieve, e.g., to increase the share of walking trips to work by $\mathrm{X} \%$. Provide well-usable and attractive products embedded in an agreeable context. The product has to be designed (e.g., infrastructure) or described and presented (e.g., the activity of walking in the city) in accordance with the citizens' needs and wishes. Necessary compromises between the work of experts (road safety, decision makers, sponsors, and budgets) and the wishes of the road users have to be explained.

- Communication (Promotion): Address citizens with arguments that meet acceptance and do not forget the downsides (e.g., shortcomings of the preconditions for walking that have developed historically). Information, instructions, PR measures and advertising, etc. have to be provided in such a way that they will attract the interest of the persons being addressed and will appeal to them (i.e., match their motivational status).

- Incentives (Promotion): Provide opportunities to test the product and to experience it as convenient and useful. These measures help to provide direct (contingent) reinforcement for the citizens if they "use the product" (in our case: if they behave in the wished-for way $=$ if they walk).

- Distribution (Placement): Place product, communication, and incentive measures efficiently in order to achieve a high probability that citizens will become well aware of them-geographically, in the media.

- Holistic approach: A combination of all the above-mentioned aspects and steps is necessary for a successful marketing process.

Figure 1. Suggestion for a simplified model for marketing walking (summary table compiled by the authors).

Appropriate segmentation will optimise such a procedure. As mentioned above, a stimulus (in this case a product) has to match the motivation of individuals in order to be noticed.

The concept of a holistic approach refers to the importance of the fact that marketing in the sense used by Kotler has its best effects if all measures are used in a concerted way. Otherwise there will be losses of effectiveness and efficiency. For instance, a lack of knowledge about good preconditions for walking (poor communication) will lead to sub-optimal appreciation of these preconditions by the users, while convincing communication that gets people to walk, but then they find out that the preconditions are unsatisfactory, may result in a boomerang effect: "I tried it. It worked so badly that I will never do it again" [24-26].

\section{The Procedure}

How should one proceed when applying the marketing model in the frame of practical work that has the goal to convince people to walk more? We introduce a suggestion for such a procedure that has the goal of boosting walking as a sustainable traffic mode. This procedure is described below in Figure 2. 


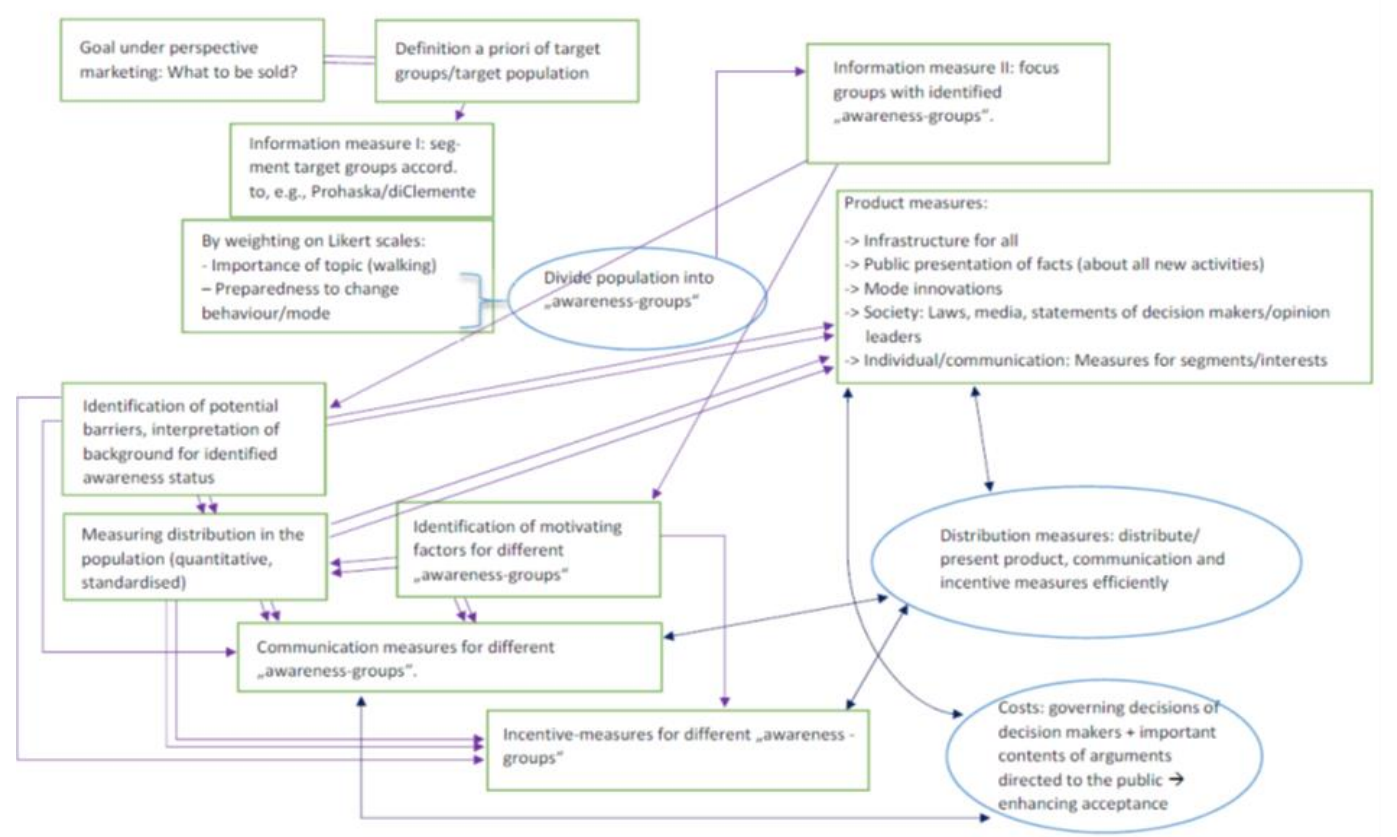

Figure 2. The suggested procedure according to the model.

The first step is a clear definition of what we want to sell (the product) and of the target population to whom we want to sell the product. At this stage the target population is only defined generally. The next step is a segmentation of the target population on the basis of their attitudes towards the suggested change and their intentions (see below). The next stage is the identification of barriers and motivating factors among all groups, using interviews or focus groups or other qualitative data collection methods, and to compare results from these work steps to existing literature, thus completing the existing knowledge base [16]. In the next step, on the basis of the information from the interviews or focus groups, a broader data collection is needed, preferably using a questionnaire on a large sample of citizens.

On the basis of this information a product (what do we want to sell?) can be designed and communicated in a way which will follow the needs and motivations of our target group, or, better to say, the different subgroups. In our case the product is "to walk more" and the relevant measures are the (further) development of an infrastructure that is friendly to pedestrians, of social norms that support walking, of institutional activities, and of laws that support walking, etc. Once this is done an appropriate communication strategy has to be chosen in order to reach the target populations, to deliver the message (information) in such a way that it reaches the target groups, and to persuade them (motives). In line with this, incentive measures have to be thought of and introduced. All the activities need to be distributed and placed in such a way that they reach as many members of the different target groups as possible. As can easily be seen, not all of this work can be done according to textbooks, but creativity is needed, as well as thorough study of experiences in other countries and cities.

\subsection{Segment the Population}

When we know what should be sold, it will be necessary to define in more detail to whom it shall be sold. In our case the idea of walking (more) should be "bought" by many (more) citizens than those that "buy it" nowadays. Both persons who already consider themselves to be walkers (whom we want to keep as walkers) and people that we want to convince to walk (more), i.e., those that should become our "customers", need to be addressed. A division between walkers and non-walkers, in a first step, could be achieved by simply asking "Do you consider yourself a walker?" with the answer options Yes or No. This is certainly rough and imprecise. Asking additional questions, such as "How many times a week do you walk?", "What purposes do you walk for?", "What distances do you usually walk, 
then?", etc. could help to get data in order to learn what frequencies of walking, which destinations, and what distances walked are associated with considering oneself a walker.

The group of non-walkers can be divided into subgroups with different statuses of self-awareness. Our suggestion is to detect different statuses of self-awareness by applying the model of Prochaska [27] (see Figure 3), e.g., according to the importance attributed to walking and the (expressed) preparedness to "buy" the "product", i.e., to walk more. The stages of change according to this model are: 1) Pre-contemplation - where the individual has no intention of changing his/her behavior and even resists change; 2) Contemplation-where the individual starts to become aware of the problem, but without any concrete intentions yet; 3) Preparation-where the individual starts developing preparations for change; 4) Action-where change has occurred but where there is still the risk that the individual could revert to their previous behavior patterns; 5) Maintenance-where the new behavior starts becoming a habit, and 6) Termination-where the new behavior is established and the individual is not likely to revert to their old behavior. We would consider people in stages 1 to 3 to be non-walkers, according to this model.

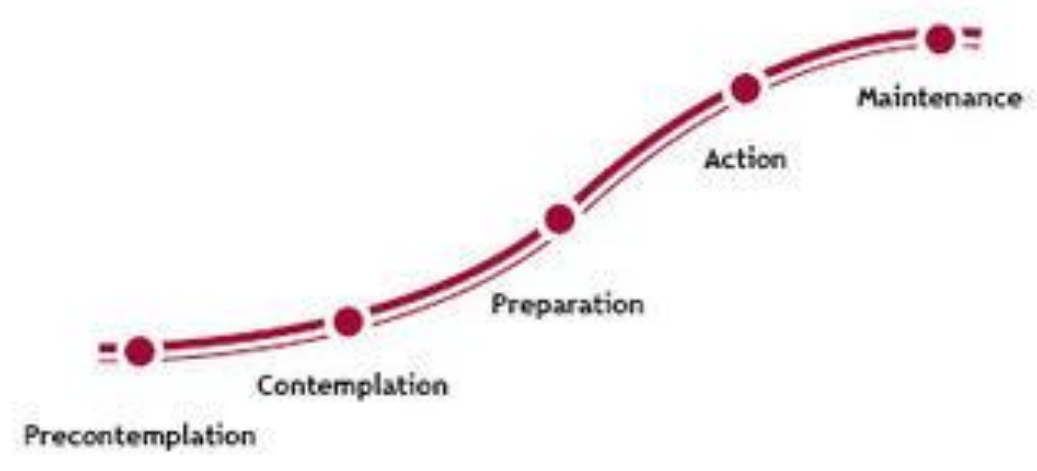

Figure 3. The stages of change according to the Transtheoretical model [27].

We suggest that the importance attributed to walking and the preparedness to walk (more)-i.e., to change one's behavior-are used in combination in order to define what we would like to call self-awareness groups according to the model of Prochaska [27]. To start with, an easy and still rather clumsy way to identify the state of self-awareness of a person is to have this person answer two simple questions on Likert scales: (1) How important is walking as a transport mode in your eyes? (scale: not important at all-very important), and; (2) Are you considering walking more in the future? (scale: I am certainly not considering this-I certainly am). The question is, of course, how to combine these two variables and which weight to give to each of them. We suggest applying the following calculation that could be improved and refined step by step later on: give an answer scale from 5 (totally unimportant) to 9 (very important) concerning "Importance $=\mathrm{I}^{\text {", }}$, to the first question and another scale from 5 (I am not considering change at all) to 1 (I am definitely considering change very strongly) to "Considering Change $=\mathrm{CC}^{\prime \prime}$ and divide $\mathrm{I} / \mathrm{CC}$, thereby arriving at results according to the formula

$$
1 \leq \mathrm{I} / \mathrm{CC} \leq 9
$$

that are displayed in Table 1 below:

Table 1. Values produced by the suggested model for how to combine "I" and "CC" (I/CC).

\begin{tabular}{cccccc}
\hline $\begin{array}{c}\text { "I" } \\
\text { "CC" }\end{array}$ & $\begin{array}{c}\mathbf{5} \\
\text { Totally Unimportant }\end{array}$ & $\begin{array}{c}\mathbf{6} \\
\text { Unimportant }\end{array}$ & $\begin{array}{c}\mathbf{7} \\
\text { Neutral }\end{array}$ & $\begin{array}{c}\mathbf{8} \\
\text { Important }\end{array}$ & $\begin{array}{c}\mathbf{9} \\
\text { Very Important }\end{array}$ \\
\hline no plans at all 5 & 1 & 1.2 & 1.4 & 1.6 & 1.8 \\
\hline not really 4 & 1.25 & 1.5 & 1.75 & 2 & 2.25 \\
\hline not yet decided 3 & 1.6 & 2 & 2.3 & 2.6 & 3 \\
\hline there are plans 2 & 2.5 & 3 & 3.5 & 4 & 4.5 \\
\hline very clear plans 1 & 5 & 6 & 7 & 8 & 9 \\
\hline
\end{tabular}


This model attributes more weight to the consideration of changing one's mode choice and less weight to the importance attributed to such a change. This follows the logic that the outcome is relevant; whether there is a chance that people change their behavior is more relevant than the importance attributed to the goal of such a change-namely that more people walk more. (A long discussion could be led concerning the relationship between the importance attributed to walking and the preparedness to walk (more). The two are certainly not independent of each other. However, we leave that discussion until later, i.e., on other occasions, as a separate topic of research. It is clear that the quality of the procedure that we suggest here suffers, but as we stated: This paper presents a first suggestion as to how to proceed. If our arguments are stringent enough, further work will lead to more experience and better understanding of the whole process of "selling walking"). We suggest that the value 1 represents people in the pre-contemplation phase, values from above 1 to below 1.75 the contemplation phase, from 1.75 to below 2.6 the preparation phase, from 2.6 to below 4 the action phase, and values of 4 and above 4 the maintenance phase.

\subsection{Inform Yourself About the Different Segments of Your Population}

Once the target population has been divided into subgroups according to the above-mentioned model a systematic dialogue should start, in order to find out how the different groups perceive walking in relation to their own mobility and mode choice; what makes walking attractive, in their eyes, and what makes it difficult? What are the barriers that keep (so many) people from walking (more often)? As a procedure for carrying out such a dialogue we suggest a mixed-methods approach, as proposed by Creswell and Plano Clark [28]. They suggest combining qualitative and quantitative ways of questioning people. Qualitative ways of asking people are focus group interviews, narrative interviews, semi-structured interviews, etc., all types of dialogues where it is possible to ask for the "why" of certain attitudes, motives, habits, and behaviors [29]. Questions about why one does not, for example, like to walk have to be answered in the person's own words. The explanations can be longer and differentiated and help to provide an understanding of the person's motives. The qualitative part of the questioning thus helps to find many different explanations that could play a role in connection with any issue that is relevant for the populations that are addressed [30]. If one wants to find out what could lie behind the pleasure that certain persons perceive in connection with walking, or behind the reluctance to walk of others, a qualitative approach is the way of choice. Qualitative questioning is usually carried out following the principle of saturation. This means that the researcher (preferably the psychologist) realises that no new explanations are being given at a certain point in time, i.e., that everything that could be relevant has been mentioned. The question as to how many persons are asked thus depends on when saturation is reached. The process to reach saturation depends of course on the character of the population [31]. At that point the researcher has a list in his hands with as many possible explanations for a certain behavior (attitudes, motives, habits, prejudices, etc.) as is possible in this case. In connection with qualitative questioning, representativeness is not an issue. The goal is to collect explanations that play a role for the people being interviewed and that could play a role for the entire population [31].

To find out what role the explanation plays for the entire population a quantitative and representative approach is needed and has to be added. To this end, what has been learned in the frame of the qualitative procedures is transformed into an instrument that can be answered by ticking or by scaling pre-formulated answers to questions. The sample of people that is questioned in this way needs to be representative, as mentioned above. This means that a statistically relevant segment of those people whose position we want to understand needs to be questioned. For instance, the statement that group A is put off by the noise produced by motor vehicles more than group B has to be based on a thorough procedure concerning the sampling of the people that should be asked. Generally, we can say that representativeness is assured when our research sample has the same characteristics (e.g., age, gender) as the basic population (e.g., all citizens, or all the inhabitants of the selected area) [32]. 
To structure the answers received in the frame of the qualitative dialogue with the population, different ways can be chosen. Here, we want to suggest making use of the usability principle according to the International Organisation for Standardisation, ISO/IEC 9126-4 Metrics (Software engineering-Product quality-Part 4: Quality in use metrics [33]. It specifies that the concept of usability reflects "the extent to which a product can be used by specified users to achieve specified goals with effectiveness, efficiency and satisfaction in a specified context of use" [33]. The effectiveness of any product, service, or idea refers to the necessity that it clearly serves to reach defined and relevant goals. Efficiency reflects the ease and economic viability connected to adopting any new behavior or buying any new product; no exaggerated investments should be needed. Satisfaction points at the necessity that the wished-for behavior should be comfortable and feel good.

Generally, the qualitative steps have the task of detecting phenomena related to any topic that might be relevant for any defined population from the perspective of members of this population, while the quantitative ones should measure the distribution of these detected phenomena in the population that has been defined. Without this combination, formulating the questions for a standardised questionnaire that should be applied in order to achieve representative quantitative results is a risky endeavour, with some probability that the questions are irrelevant to the target group and/or that the questionnaire misses important issues. On the other hand, if we do not use a standardised questionnaire, we are unable to conclude what the distribution of the phenomenon is (e.g., barriers mentioned in the frame of the focus groups) in the target population [29].

\subsection{Design, Communication, and Delivery of the Products}

The next phase is the elaboration of product measures: Introduction and implementation, measures to protect existing optimum solutions, refinements, improvements, and innovation; infrastructure measures, presentation of facts concerning the "product", measures referring to society, laws, media, statements of decision makers. This has to be done according to what has been learned in the qualitative and quantitative analyses, with respect to the different subgroups of the target population. Product measures should, in principle, satisfy all self-awareness groups. It is not probable that e.g., infrastructure elements that satisfy one group will deter other groups. However, if this is the case-or could be the case-compromises have to be found. The elaboration of all the measures has to be carefully planned and synchronised. It has to be ensured that all measures point in the same direction and reinforce one another. If it is not possible to tackle something, e.g., to eliminate a certain barrier, it is recommended to inform citizens about this in a frank manner. To be informed about shortcomings is accepted better than being taken by surprise in experiencing this shortcoming.

In the frame of communication measures [34] one needs to address advertising, arguments, and polemics to the self-awareness groups (identified in the analysis phase). Such communication is more than presenting facts; it gives the facts a spin, reflecting why one should be interested in knowing these facts and in adhering to the ideas represented there. The communication style must have the potential to deliver the message and to persuade the audience. According to the European project CAST-Campaigns and Awareness-raising Strategies in Traffic Safety [35], a message is more likely to have an impact on behavior if the person receiving it feels motivated to process it, thinks actively about it, and elaborates upon its content. An effective message must be plausible to the audience (credible), convey a behavior that is possible to achieve (realistic), be heard repeatedly (consistent), be easy to understand (clear), be capable of generating change (persuasive), be relevant to the person (relevant), and be appealing (attractive).

One of the most important steps is to develop and implement motivation activities-incentives. They usually have the objective of converting extrinsic motivation into an intrinsic type, i.e., to provide opportunities to buy a product or to ponder, and possibly adopt, an idea and to behave accordingly, i.e., to motivate people to "buy" with the help of what is perceived as a reward according to what has been learned in the frame of the analyses. In our case, one way of supporting this could be an offer of 
a free long-term public transport ticket if one agrees to give up car use for a selected period of time (for more examples see $[36,37])$.

Finally, a central task is to distribute all these types of measures in as effective and efficient a way as possible, by attempting to reach as many people as is feasible and possible. It is important that decision makers provide important information to the public, thereby avoiding misleading information and enhancing the acceptance of measures by the public. This means that a dialogue with decision makers is essential. Thus the principle of the devil's advocate should be followed. List all the possible arguments against enhancing walking and show, according to what has been said so far, that most of these arguments have no substantial basis. Another possibility is to connect individual advantages with individual costs and make it visible that the benefits for each individual exceed the costs of the product that should be sold [35].

\section{Conclusions}

The conclusion of this paper can best be started with reference to the "holistic approach" mentioned in Figure 1 and the text that follows. Such an approach considers all types of measures a kind of orchestra that should be applied in synergy and with consideration being given to each other's status. In the frame of marketing the example of effective communication that convinces people to make use of a poor product-leading to fatal consequences-is often given. However, the orchestra is larger than that. In this respect, we suggest using the Diamond model [38] as a checklist to ensure that all the relevant domains of the traffic system are tackled by the measures that are set and, as far as possible, in an appropriate combination. There are five main domains (see Figure 4) in the frame of which measures should be defined. (1) Measures addressed to the Individual would explicitly refer to personal preferences, provide motivation, offer incentives, develop education schemes, etc. The product would be the description of these aspects. Communication and distribution refer to the quality of their presentation-with arguments and irony-and how many target populations are reached and how well. (2) Measures connected to the Transport mode will mostly be communication measures, e.g., information on the health benefits of walking and many others. Products in this area could be good shoes, bags, sticks, and accessories. All of them can be offered in the frame of incentive measures to, e.g., "the toughest walker-to-work in the company" or the like. (3) It is easy to understand that the Infrastructure area is the product area: e.g., pavements with appropriate capacity, smooth surfaces, a walking network with distances as short as possible, safe crossings with short waiting times and a sufficiently long time to cross, taking care of aesthetic aspects such as greenery and cleanliness, providing seating facilities and toilets, etc. etc. Communication would emphasise the preconditions, but as already stated, it should not do so if the preconditions are poor. If the preconditions are good, however, getting people to try walking with the help of incentives could lead to good results. The distribution aspect is clear here: the preconditions for walking should be good everywhere. (4) Societal measures, e.g., laws and public campaigns to support the development of social norms that perceive pedestrians as "smart", will be presented to the public as facts ("products"), and communication and distribution measures will see to it that they are explained well and that as many citizens as possible are informed about them in a convincing way. Fiscal measures can be implemented as incentives. (5) Finally, in the area of Communication among road users' product measures to the advantage of walking could be a reduction of vehicle speeds to reduce the gap in power between motor vehicle drivers and pedestrians, to make crossing easier, to lower noise levels, etc. Again, such measures need to be sold and distributed appropriately. It is important that all these measures, in all domains, are mutually reinforcing, consistent, and available at the moment when the information about the products reaches the target groups. 


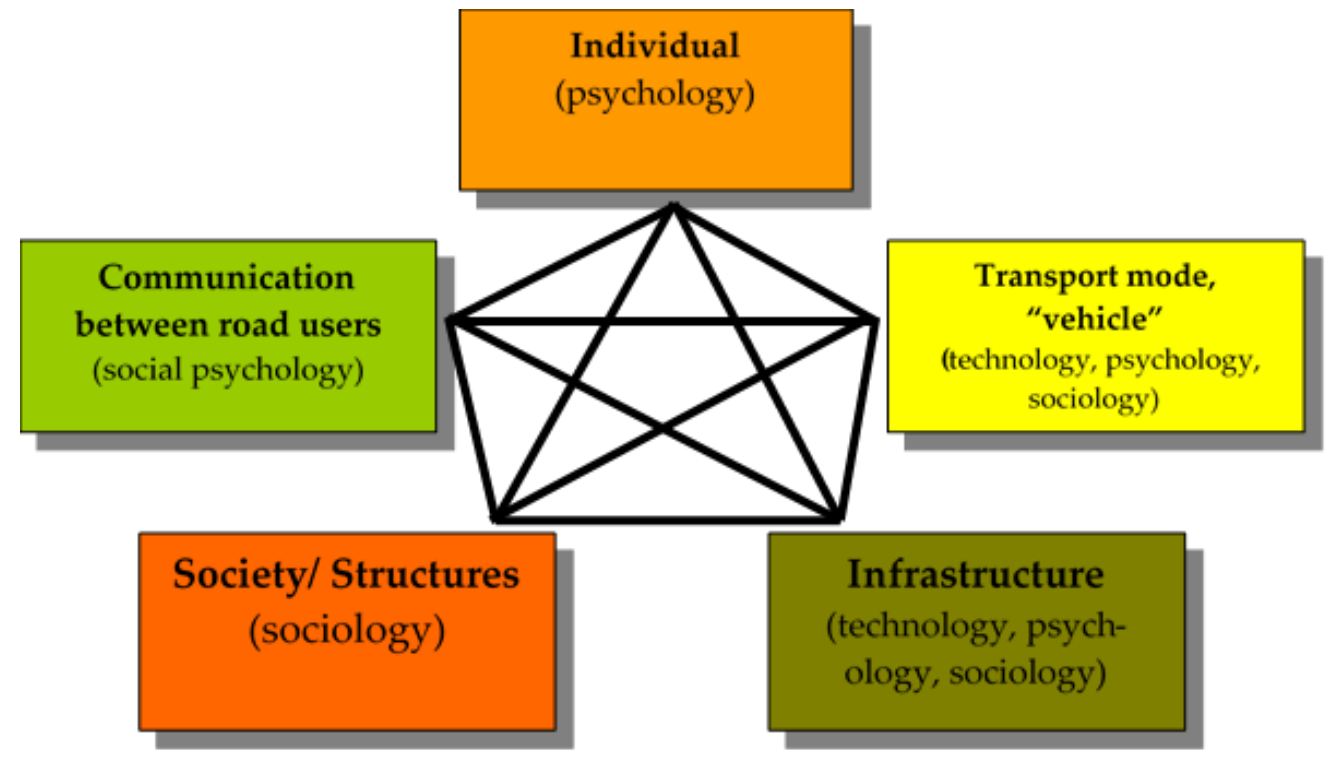

Figure 4. The Diamond model [38].

Many of the above-mentioned measures are known and have been tested, but usually as bits and pieces and nowhere (or hardly anywhere?) in a coherent, widely, well-distributed, and orchestrated manner. This means that any city or country that tried to take a holistic approach could take measures from off the shelf. However, the important point is that these measures have to be applied in combination and, what is more important, they have to be fine-tuned in order to fit the context. The most important element of this context is, however, how the citizens to be addressed perceive their everyday world. This is what all the measures taken have to be adjusted to. We hope that this paper can give some support concerning the communication with the citizens.

Author Contributions: Both authors did the literature review, wrote the manuscript. All authors have read and agreed to the published version of the manuscript.

Funding: This work received financial support for university research provided by the Ministry of Education of the Czech Republic, project No. FF_2019_016.

Conflicts of Interest: The authors declare no conflict of interest.

\section{References}

1. Grazi, F.; Bergh, J.C.V.D.; Ommeren, J.N.V. An Empirical Analysis of Urban Form, Transport, and Global Warming. Energy J. 2008, 29, 97. [CrossRef]

2. Urban Transport and Climate Change. The World Bank. 2012. Available online: https://www.worldbank. org/en/news/feature/2012/08/14/urban-transport-and-climate-change (accessed on 3 December 2019).

3. Beck, C.; Broek, S.; Degraeuwe, B.; Beusen, B.; Panis, L.I. Limits to Active Transport Substitution of Short Car Trips. Transp. Res. Part D Transp. Environ. 2013, 22, 10-13. [CrossRef]

4. Daniels, R.; Mulley, C. Explaining Walking Distance to Public Transport: The Dominance of Public Transport Supply. J. Transp. Land Use 2013, 6, 5-20. [CrossRef]

5. Lanzini, P.; Khan, S.A. Shedding Light on the Psychological and Behavioral Determinants of Travel Mode Choice: A meta-Analysis. Transp. Res. Part F Traffic Psychol. Behav. 2017, 48, 13-27. [CrossRef]

6. Ye, R.; Titheridge, H. Satisfaction with the Commute: The Role of Travel Mode Choice, Built Environment and Attitudes. Transp. Res. Part D Transp. Environ. 2017, 52, 535-547. [CrossRef]

7. Hydén, C.; Nilsson, A.; Risser, R. WALCYNG: Walking and Cycling Instead of Shorter Car Trips; Final Report; Institute for Technology \& Society. University of Lund and FACTUM: Vienna, Austria, 1997.

8. Federal Highway Administration (FHW). National Household Travel Survey. 2009. Available online: http://nhts.ornl.gov/det/Extraction3.aspx (accessed on 25 October 2019). 
9. Lindelöw, D. Walking as a Transport Mode: Examining the Role of Preconditions, Planning Aspects and Personal Traits for the Urban Pedestrian; Lund University: Lund, Sweden, 2016.

10. Panter, J.R.; Jones, A.P.; Van Sluijs, E.M. Environmental Determinants of Active Travel in Youth: A Review and Framework for Future Research. Int. J. Behav. Nutr. Phys. Act. 2008, 5, 34. [CrossRef] [PubMed]

11. Delhomme, P.; De Dobbelleer, W.; Forward, S.; Simoes, A. CAST Project-Manual for Designing, Implementing and Evaluating Road Safety Communication Campaigns; Belgian Road Safety Institute (IBSR-BIVV): Brussels, Belgium, 2009.

12. Wang, F.; Lee, E.K.O.; Wu, T.; Benson, H.; Fricchione, G.; Wang, W.; Yeung, A.S. The Effects of Tai Chi on Depression, Anxiety, and Psychological Well-Being: A Systematic Review and Meta-Analysis. Int. J. Behav. Med. 2014, 21, 605-617. [CrossRef] [PubMed]

13. Methorst, R.; Monterde, I.; Bort, H.; Risser, R.; Sauter, D.; Tight, M.; Walker, J. Pedestrians' Quality Needs PQN; Action 358; European Cooperation in Science and Technology (COST): Brussel, Belgium, 2010.

14. Kotler, P.; Burton, S.; Deans, K.; Brown, L.; Armstrong, G. Marketing; Pearson Higher Education: New York, NY, USA, 2015.

15. Ogilvie, D.; Egan, M.; Hamilton, V.; Petticrew, M. Promoting Walking and Cycling as an Alternative to Using Cars: Systematic Review. BMJ 2004, 329, 763. [CrossRef]

16. Ogilvie, D.; Foster, C.E.; Rothnie, H.; Cavill, N.; Hamilton, V.; Fitzsimons, C.F.; Mutrie, N. Interventions to Promote Walking: Systematic Review. BMJ 2007, 334, 1204. [CrossRef] [PubMed]

17. Forsyth, A.; Krizek, K.J. Promoting Walking and Bicycling: Assessing the Evidence to Assist Planners. Built Environ. 2010, 36, 429-446. [CrossRef]

18. Solnit, R. Wanderlust: A History of Walking; Verso: New York, NY, USA, 2014.

19. Kagge, E. Silence: In the Age of Noise; Penguin: London, UK, 2017.

20. Brownson, R.C.; Hagood, L.; Lovegreen, S.L.; Britton, B.; Caito, N.M.; Elliott, M.B.; McGill, J.B. A Multilevel Ecological Approach to Promoting Walking in Rural Communities. Prev. Med. 2005, 41, 837-842. [CrossRef] [PubMed]

21. Pooley, C.G. Promoting Walking and Cycling; Policy Press: Bristol, UK, 2013.

22. Raghunathan, R.; Trope, Y. Walking the Tightrope between Feeling Good and Being Accurate: Mood as a Resource in Processing Persuasive Messages. J. Personal. Soc. Psychol. 2002, 83, 510. [CrossRef]

23. Leinbergerm, C.B.; Rodriguez, M. Foot Traffic Ahead. Ranking Walkable Urbanism in America's Largest Metros; The George Washington University School of Business: Washington, DC, USA, 2016.

24. Şimşekoğlu, Ö.; Nordfjærn, T.; Rundmo, T. The Role of Attitudes, Transport Priorities, and Car Use Habit for Travel Mode Use and Intentions to Use Public Transportation in an Urban Norwegian public. Transp. Policy 2015, 42, 113-120. [CrossRef]

25. Forward, S. Walking, Communication and Practice: Attitudes and Motivations. In Proceedings of the 14th International Cooperation on Theories and Concepts in Traffic Safety Workshop, Caserta, Italy, 25-26 October 2001.

26. Scheepers, E.; Wendel-Vos, W.; van Kempen, E.; Panis, L.I.; Maas, J.; Stipdonk, H.; Schuit, J. Personal and Environmental Characteristics Associated with Choice of Active Transport Modes Versus Car Use for Different Trip Purposes of Trips up to 7.5 Kilometers in The Netherlands. PLoS ONE 2013, 8, e73105. [CrossRef] [PubMed]

27. Prochaska, J.O.; DiClemente, C.C.; Norcross, J.C. In search of How People Change: Applications to Addictive Behaviors. Am. Psychol. 1992, 47, 1102-1114. [CrossRef] [PubMed]

28. Creswell, J.W.; Plano Clark, V.L. Designing and Conducting Mixed Methods Research, 3rd ed.; SAGE Publications: London, UK, 2018.

29. Liamputtong, P.; Ezzy, D. Qualitative Research Methods; Oxford University Press: Melbourne, Australia, 2005; Volume 2.

30. Darker, C.D.; Larkin, M.; French, D.P. An Exploration of Walking Behaviour-An Interpretative Phenomenological Approach. Soc. Sci. Med. 2007, 65, 2172-2183. [CrossRef] [PubMed]

31. Saunders, B.; Sim, J.; Kingstone, T.; Baker, S.; Waterfield, J.; Bartlam, B.; Burroughs, H.; Jinks, C. Saturation in Qualitative Research: Exploring Its Conceptualization and Operationalization. Qual. Quant. 2018, 52, 1893-1907. [CrossRef] 
32. Saylor Academy. Principles of Sociological Inquiry: Qualitative and Quantitative Methods. 2012. Available online: https://saylordotorg.github.io/text_principles-of-sociological-inquiry-qualitative-and-quantitativemethods/index.html (accessed on 3 December 2019).

33. Koohang, A. Expanding the Concept of Usability, University of Wisconsin. Inf. Sci. J. 2004, 7, $129-141$.

34. Delhomme, P.; Vaa, T.; Meyer, T.; Goldenbeld, C.; Jaermark, S.; Christie, N.; Rehnova, V. Deliverable 4: Evaluated Road Safety Media Campaigns: an Overview of 265 Evaluated Campaigns and Some Meta-Analyses on Accidents; GADGET project (NO RO-97-SC. 2235); INRETS: Arcueil, France, 1999.

35. Road Safety Communication Campaigns. A Final Deliverable from The Project CAST-Campaigns and Awarenessraising Strategies in Traffic Safety; European Union: Brussels, Belgium, 2010.

36. Richter, J.; Friman, M.; Gärling, T. Soft Transport Policy Measures: Gaps in Knowledge. Int. J. Sustain. Transp. 2011, 5, 199-215. [CrossRef]

37. Matthies, E.; Klöckner, C.A.; Preißner, C.L. Applying a Modified Moral Decision Making Model to Change Habitual Car Use: How Can Commitment Be Effective? Appl. Psychol. 2006, 55, 91-106. [CrossRef]

38. Risser, R. Measuring Influences of Speed Reduction on Subjective Safety. In Proceedings of the Workshop on Traffic Calming, ICTCT, New Delhi, India, 15 March 2000.

(C) 2020 by the authors. Licensee MDPI, Basel, Switzerland. This article is an open access article distributed under the terms and conditions of the Creative Commons Attribution (CC BY) license (http://creativecommons.org/licenses/by/4.0/). 